\title{
Editorial
}

\section{Continuing COVID vaccination will break the chain of virus transmission: myth or reality}

\author{
Achhelal R. Pasi* \\ Airport Health Organisation, The Directorate General of Health Services, Ministry of Health and Family Welfare - \\ Government of India, Mumbai, Maharashtra, India \\ Received: 12 March 2021 \\ Accepted: 12 April 2021 \\ *Correspondence: \\ Dr. Achhelal R. Pasi, \\ E-mail: arl23_pasi@yahoo.co.in \\ Copyright: ( ) the author(s), publisher and licensee Medip Academy. This is an open-access article distributed under \\ the terms of the Creative Commons Attribution Non-Commercial License, which permits unrestricted non-commercial \\ use, distribution, and reproduction in any medium, provided the original work is properly cited.
}

COVID-19 is the disease caused by severe acute respiratory syndrome coronavirus 2 (SARS-CoV-2) whose main mode of transmission between people, is when an infected person is in close contact with another person, apart from fomite and airborne transmission. ${ }^{1}$ Infection occurs when virus enters in the body and begin to multiply while disease occurs when the cells in the body are damaged — as a result of the infection — and signs and symptoms of an illness appear. ${ }^{2}$ Approximately $40 \%$ to $45 \%$ of those infected with SARS-CoV-2 remain asymptomatic and asymptomatic persons can transmit SARS-CoV-2 to others. ${ }^{3}$ Asymptomatic SARS-CoV-2 infections have been demonstrated to present with viral loads similar to symptomatic infections. ${ }^{3,4}$ Contact tracing and modelling studies suggest presymptomatic and asymptomatic patients are responsible for approximately $50 \%$ of all COVID-19 transmission events. ${ }^{5,6}$

There are six points at which the chain of transmission can be broken and virus can be stopped from infecting another person. The six links include: the infectious agent, reservoir, portal of exit, mode of transmission, portal of entry, and susceptible host. ${ }^{7}$ Ideally, the vaccine should prevent virus infection and transmission as well as preventing COVID-19 disease. Currently, as countries roll out vaccines that prevent COVID-19, the scientific community cannot state with certainty that the current vaccines prevent person to person transmission. ${ }^{8}$ The purpose of COVID-19 vaccines ideally is to prevent death or evert serious health complications that strain our health care system. All the vaccines authorised for emergency use do this. ${ }^{8}$ However there are no conclusive evidence that the COVID-19 vaccine prevents the infection.

\section{COVID-19 vaccine}

Currently, there are three main types of COVID-19 vaccines namely messenger ribonucleic acid (mRNA) vaccine, Protein subunit vaccines and vector subunit vaccines. India, the country which is second most impacted by COVID-19 has secured approvals for two indigenous vaccines on an emergency basis- covaxin and covishield. ${ }^{9}$

Covishield or AZD-1222 makes use of a viral vector made using a weakened strain of the common cold virus (adenovirus), which contains genetic material similar to that of SARS-COV-2. Upon administration, the body's defences recognize the spike protein and prepare antibodies to evade out the infection.

Similarly, covaxin is made using an inactive version of the virus- i.e. the vaccine inactivates the virus's ability to replicate but sustains its life so that the immune system could mount a sufficient response when it comes in contact or recognizes an attack on the body in the future. ${ }^{9,10}$

Epidemiology, including disease transmission dynamics, of pulmonary tuberculosis (TB) and COVID-19 are same. TB and COVID-19 are both infectious diseases that attack primarily the lungs. Both diseases have similar symptoms such as cough, fever and difficulty breathing. TB, however, has a longer incubation period with a slower onset of disease. ${ }^{11}$

The bacillus Calmette-Guerin (BCG) vaccine has been in use for more than 100 years, and is regarded as one of the oldest human vaccines known today. It is recommended 
primarily due to its effect in preventing the most severe forms of tuberculosis, including disseminated tuberculosis and meningeal tuberculosis in children; however, its efficacy in preventing pulmonary tuberculosis and TB reactivation in adults has been questioned. ${ }^{12}$

With over 4 billion administered doses worldwide, and an additional 100 million new-borns being vaccinated annually, BCG is currently the most widely used vaccines in the world. Available data proves that BCG vaccine has role in reducing the morbidity and mortality but there is little evidence to say that BCG vaccine breaks the chain of transmission of TB infection. ${ }^{13}$

In respect of COVID-19 it is pertinent and that the disease cannot happen without the virus but the virus can remain in human body without causing the disease. These group of persons, who are infected but not diseased can be asymptomatic or presymtomatic. The asymptomatic and presymptomatic persons can transmit the virus without getting affected and it is difficult to distinguish between asymptomatic and presymtomatic persons. COVID-19 vaccine prevents the severe form of disease, it doesn't prevent the infection.

Interestingly, a person who is fully vaccinated may not suffer from the COVID-19 but the virus can enter in the body of the fully vaccinated individual and get transmitted to other persons also. This is the underlying reason why all vaccinated individuals should also be continuing to follow COVID prevention protocol. ${ }^{14}$

Current and available data suggests that the vaccines will at best, partly reduce transmission, and the studies to clarify and determine this are underway. It would only be prudent to wait for more data and conclusive evidence to make a statement like "ongoing COVID vaccination will break the chain of transmission".

A public health statement that need to resonate with reason is that a vaccine that is highly effective at preventing people from acquiring infection would help to reduce transmission, and till then everyone, irrespective of vaccination status need to follow the COVID prevention measures.

The best way to prevent infection from COVID-19 is to avoid exposure to the virus. The virus spreads mainly from person-to-person through close contact. The basic preventive measures include simple public health measures that are to be followed to reduce the risk of infection with COVID-19. These measures must always be observed by all individuals. These include: physical distancing, use of mask, hand hygiene, respiratory hygiene, prompt isolation and prompt testing. ${ }^{15}$

\section{Funding: No funding sources \\ Conflict of interest: None declared \\ Ethical approval: Not required}

\section{REFERENCES}

1. Corona Virus Disease (COVID - 19). Available at: https://www.who.int/emergencies/diseases/novelcoronavirus-2019/question-and-answers-hub/q-adetail/coronavirus-disease-covid-19. Accessed on 05 March 2021.

2. Understanding infection vs. disease. Available at: https://www.mayoclinic.org/diseases-conditions/inf ectious-diseases/in-depth/germs/art 20045289\#: :tex $\mathrm{t}=$ Infection\%2C\%20often\%20the\%20first\%20step,s ymptoms\%20of\%20an\%20illness\%20appear.

Accessed on 05 March 2021.

3. Oran DP, Topol EJ. Prevalence of Asymptomatic SARS-CoV-2 Infection: A Narrative Review. Ann Intern Med. 2020;M20-3012.

4. Lee S, Kim T, Lee E, Lee C, Kim H, Rhee H, et al. Clinical Course and Molecular Viral Shedding Among Asymptomatic and Symptomatic Patients With SARS-CoV-2 Infection in a Community Treatment Center in the Republic of Korea. JAMA Intern Med. 2020;180:1447.

5. Moghadas SM, Fitzpatrick MC, Sah P, Pandey A, Shoukat A, Singer BH, et al. The implications of silent transmission for the control of COVID-19 outbreaks. PNAS. 2020;117:17513-5.

6. Du Z, Xu X, Wu Y, Wang L, Cowling BJ, Meyers LA. Serial Interval of COVID-19 among Publicly Reported Confirmed Cases. Emerg Infect Dis. 2020;26:1341-3.

7. Infection prevention and you: breaking the chain of transmission. Available at: http://www.ashnha. com/wp-content/uploads/2017/10/Break-the-Chainof-Infection.pdf. Accessed on 05 March 2021.

8. Does the COVID vaccine stop transmission? Available at: https://economictimes.indiatimes.com/ news/international/world-news/does-the-covid-19vaccine-stop-transmission/articleshow/81183856.cm s?from=mdr. Accessed on 05 March 2021.

9. Types of Vaccines. Available at: https://www.cdc.gov/coronavirus/2019-ncov/vacc ines/different-vaccines/how-they-work.html. Accessed on 05 March 2021.

10. Coronavirus vaccine: Covishield vs. Covaxin, all you need to know about India's approved homegrown vaccines. Available at: https://timesofindia.india times.com/life-style/health-fitness/health-news/ coronavirus-vaccine-covishield-vs-covaxin-all-youneed-to-know-about-indias-approved-homegrownvaccines/photostory/80091866.cms. Accessed on 05 March 2021.

11. Tuberculosis and COVID-19. Available at: https://www.who.int/teams/global-tuberculosisprogramme/covid-19\#: :text=Tuberculosis\%20(TB) $\% 20$ and,slower\%20onset\%20of\%20disease.

Accessed on 05 March 2021.

12. Adesanya OA, Christabel I, Uche-Orji, Adedeji YA. Bacillus Calmette-Guerin (BCG): the adroit vaccine AIMS Microbiol. 2000;7(1):96-113. 
13. Comstock G. The International tuberculosis campaign: a pioneering venture in mass vaccination and research. Clin Infect Dis. 1994;19:528-40.

14. Fully vaccinated against COVID-19? Here are dos, don'ts by CDC and word of caution on variants. Available at: https://www.hindustantimes.com /world-news/fully-vaccinated-against-covid-19here-s-cdc-s-list-of-dos-and-donts-1016152844065 27.html. Accessed on 05 March 2021.

15. COVID-19 vaccines: Operational guidelines; Ministry of Health \& Family Welfare, GOI.
Available at: https://www.mohfw.gov.in/pdf/COVID 19VaccineOG111Chapter16.pdf. Accessed on 11 March 2021.

Cite this article as: Pasi AR. Continuing COVID vaccination will break the chain of virus transmission: myth or reality. Int J Community Med Public Health 2021;8:2622-4. 